\title{
EFFECT OF SINTERING AND CORDIERITE ADDITIVES ON THE PHYSICAL AND MECHANICAL PROPERTIES OF MULLITE BASED CERAMICS PREPARED FROM IRAQI RAW MATERIALS
}

\author{
${ }^{1}$ Mojahid Mohammed Najim* and ${ }^{\mathbf{1} B a n}$ Ayyoub Yousif \\ ${ }^{1}$ Department of Applied Science, University of Technology, Baghdad, Iraq \\ *E-mail: 100171@uotechnology.edu.iq
}

Received: 25 July 2020; accepted: 4 November 2020

\begin{abstract}
Mullite and cordierite are produced in the laboratory from Iraqi raw materials, have been crushed individually to obtain dense ceramic bodies to a particle size smaller than $45 \mu$. Five mixtures of cordierite and mullite have been prepared in which cordierite has been added to mullite with the percentages of 30, 40, 50, 60, and $70 \%$. One hundred and twenty disk samples have been prepared using the semi-dry pressing method, with the pressure of $1000 \mathrm{~kg} / \mathrm{cm}^{2}$. The samples were dried and fired at different temperatures of 1300, 1350, 1400 , and $1450^{\circ} \mathrm{C}$, with a soaking time of $2 \mathrm{~h}$. Physical evaluation tests (volume shrinkage, water absorption, apparent porosity, and bulk density) in addition to mechanical evaluation tests (compressive strength) have been performed. Samples fired at $1400^{\circ} \mathrm{C}$ showed the best rates for the evaluation tests in general, in which the apparent porosity and water absorption for the samples were very low while the rates of density and compressive strength were high. The characteristics of samples fired at $1450^{\circ} \mathrm{C}$ were overall poor while samples containing 60 and $70 \%$ cordierite were melted. The best samples in this investigation were proven to be the ones containing $30 \%$ cordierite and $70 \%$ mullite while samples made out of $40 \%$ cordierite and $60 \%$ mullite show good mechanical and physical characteristics. The best ideal sample was the one fired at $1400{ }^{\circ} \mathrm{C}$ and contained $30 \%$ cordierite and $70 \%$ mullite.
\end{abstract}

Keywords: Ceramic; Mullite; Cordierite; Porosity

\section{INTRODUCTION}

To use one type of ceramic that has all the properties required in application is not possible. Therefore, there is no preferred type of ceramics that is capable of meeting all of the required engineering specifications. Each type of ceramic has its characteristics. The main advantage of using ceramics is its ability to work in high temperatures and different weather conditions 
without any changes occurring in its chemical, mechanical or physical properties (Shyam et al., 2012). These properties depend on the purity of the raw materials used quality of firing and the type of ceramic's constituents (Anggono, 2005). Ceramic contains crystal structures, which are joined together with differing forces, these forces are established during the firing operations due to the chemical reactions occurring between the raw materials of the original structures. Therefore, the properties of the ceramic product depend on the degree of the crystal and amorphous phases in the ceramic. The firing operation plays an important role in determining the crystal structures and the rates of the phases that appear in the final product. Hence, the existence of high percentages of a glass phase or the appearance of any unwanted crystal phase can result in a product with poor properties (Rasteiro et al., 2007).

The need to establish the engineering ceramics industry that has recently been implemented in industrialized countries has achieved rapid development as a result of the increasing number of applications for this type of ceramics. Firstly, must initiate an engineering ceramics industry project in our country, Finally, finding a base that supports the engineering ceramics industry by knowing the best local raw materials that can be used in this field and developing these raw materials. This allows for the diversification and development of the industry through the manufacture of new and more advanced ceramic products. Mullite consists of aluminum silicate $\mathrm{Al}_{2} \mathrm{O}_{3}=71.8 \%$, and $\mathrm{SiO}_{2}=28.2 \%$, which goes back to the $\mathrm{Al}_{2} \mathrm{O}_{3}-$ $\mathrm{SiO}_{2}$ system (Fig .1), that is rarely found in nature on the island of Mall in western Scotland, which was named after mullite (Anggono, 2005).

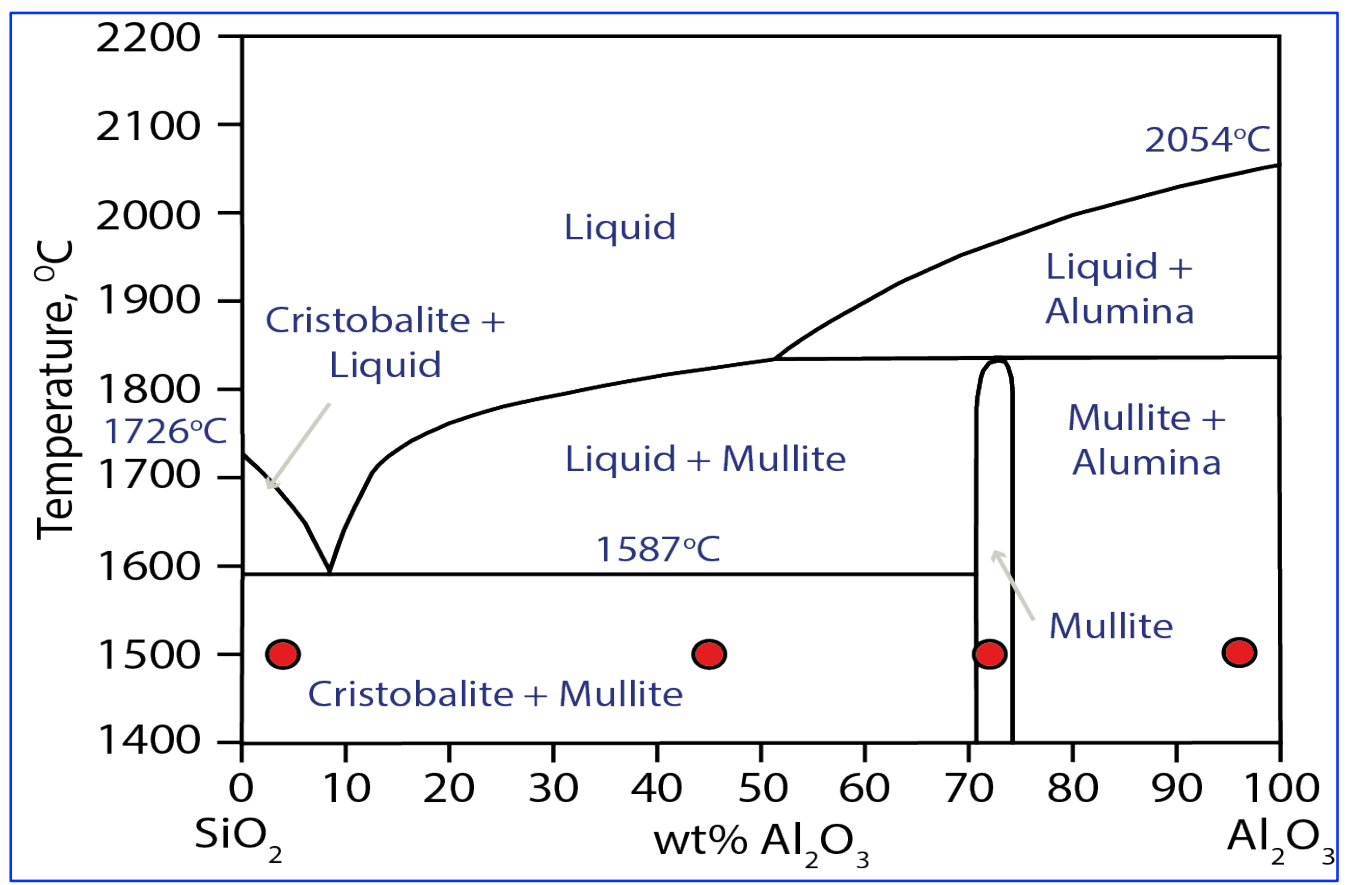

Fig. 1. Crystallization system $\mathrm{Al}_{2} \mathrm{O}_{3}-\mathrm{SiO}_{2}$ (Pask, 1988) 
Mullite with the chemical structure of $\left(3 \mathrm{Al}_{2} \mathrm{O}_{3} \cdot 2 \mathrm{SiO}_{2}\right)$ when crystallized obtains an

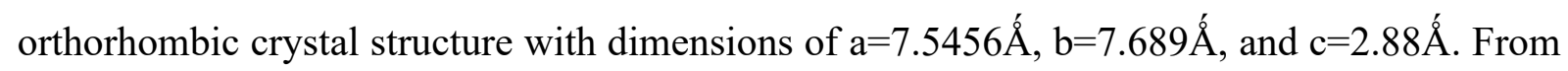
its metallic characteristics, it is colorless, has parallel extinction, a density of $3.20 \mathrm{~g} / \mathrm{cm}^{3}$, specific weight of 3.03, hardness of 7.5 (Moh's hardness scale), and needle shape that gives mullite high strength (Suriyanarayanan et al., 2009). Cordierite $\left(2 \mathrm{MgO} .2 \mathrm{Al}_{2} \mathrm{O}_{3} .5 \mathrm{SiO}_{2}\right)$ which has the system of $\left(\mathrm{MgO}-\mathrm{SiO}_{2}-\mathrm{Al}_{2} \mathrm{O}_{3}\right)$ consists of magnesium and aluminum silicate $\mathrm{MgO}=13.8 \%, \mathrm{Al}_{2} \mathrm{O}_{3}=34.8 \%$, and $\mathrm{SiO}_{2}=51.4 \%$ (Grosjean, 1993) (Fig. 2).

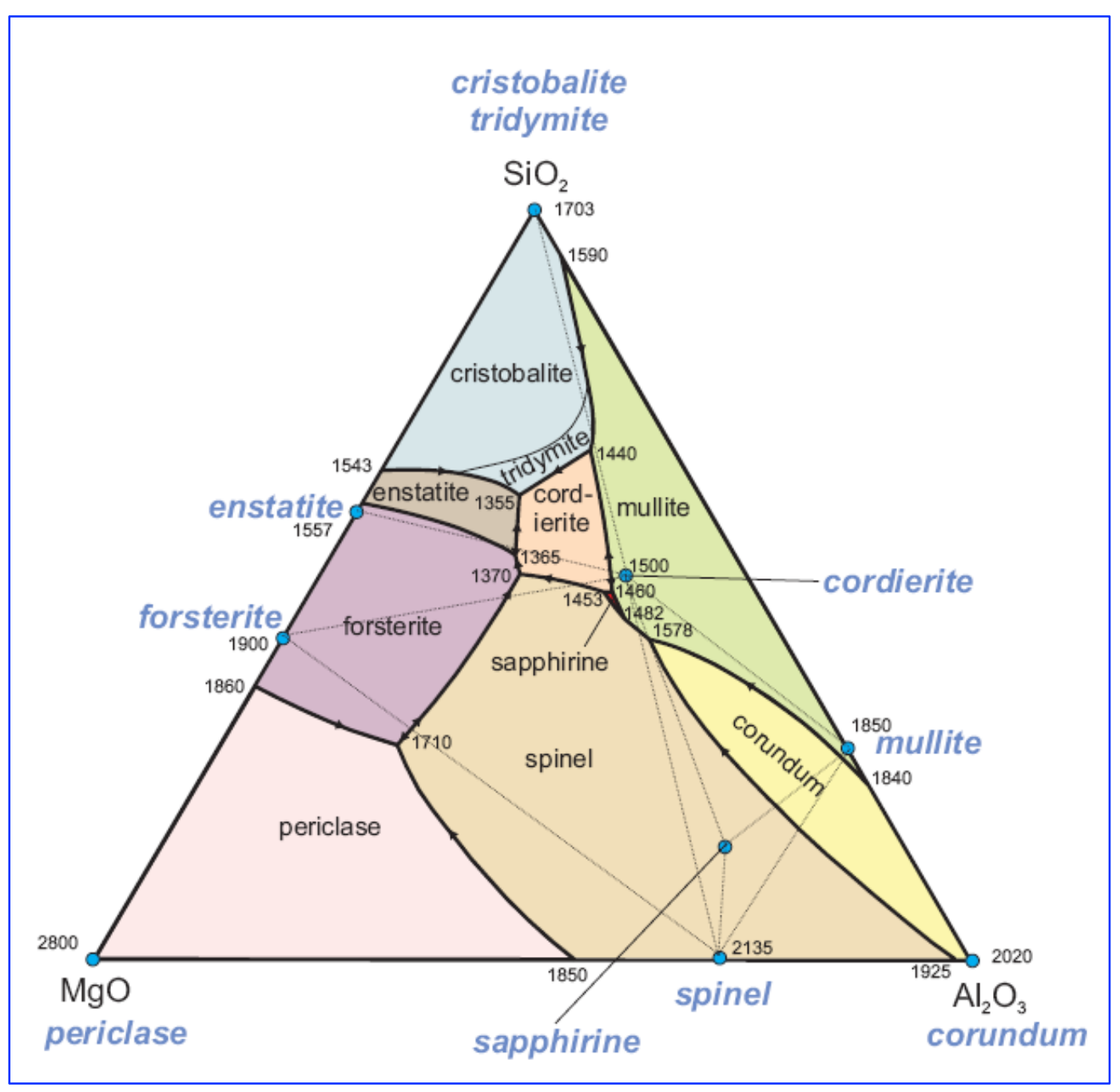

Fig. 2. Silica-alumina-magnesia system and the location of cordierite (Chester, 1973)

Cordierite has the hardness of 7-7.5 and specific weight of 2.3. Cordierite can be found in three types, in low temperatures, it crystallizes into $\beta$-cordierite that is known as low temperature orthorhombic cordierite if temperature increased turns into hexagonal high temperature cordierite or $\alpha$-cordierite which is also known as Indialite. There is another unstable phase of cordierite called $\mu$-cordierite that is crystallized from either a melt or can be 
prepared from fine materials (Bras et al., 2009; Sembiring et al., 2016). Stable cordierite can be formed in temperatures up to $1460{ }^{\circ} \mathrm{C}$, at this temperature it starts to melt incongruently forming mullite and glass (Hamzawy and Ali, 2006). Sabri (2001) prepared mullite from bauxite mineral and amorphous silica by adding $\mathrm{MgCO}_{3}$ as a mineralizing material to the mixture and using the mechano-chemical method, the structure of the chemical mixture was close to that of the standard mullite.

Shukur (2002) prepared cordierite from its three oxide constituents; magnesium oxide, aluminum oxide, and silicon oxide, in addition to preparing it from shale rocks. Both double and single firing methods have been used in order to prepare the cordierite. The $\mathrm{x}$-ray diffraction of both firing methods shows that only two samples being investigated contain $\alpha$ cordierite shows a crystal structure for cordierite glass by turning into $\mu$-cordierite at $968{ }^{\circ} \mathrm{C}$ before being changed into $\alpha$-cordierite at temperatures higher than $1000{ }^{\circ} \mathrm{C}$. $\alpha$-cordierite shows continuous growth with the increase of the sintering temperatures until it changes back again to $\mu$-cordierite at $1440{ }^{\circ} \mathrm{C}$ before it reaches the critical transition temperature that is followed by it melting at $1455^{\circ} \mathrm{C}$. The research aims to assess the local raw materials to study their usability and suitability in producing electrical ceramic insulators, and preparing of ceramic samples consisting of different ratios of cordierite and mullite powder. Studying their physical and mechanical properties and compared with international standards and specifications for electrical ceramic insulators, to this comparison it is determined that the mixtures of these samples can be used in the production of electrical ceramic insulators from local raw materials.

\section{MATERIALS AND METHODS}

\section{Preparation of Mixture}

To prepare mixture consisting of a mullite and cordierite mix produced from Iraqi raw materials (Urdhuma silica sand, Duekhla Kaolinitic clays tone, alongside other materials pure silica created as by-product of Qaim phosphate manufacturing processes and $\mathrm{MgCO}_{3}$.), crushed cordierite was added to mullite in weight percentages of $(30,40,50,60$ and $70 \%$ which were given the symbols of A, B, C, D and E respectively (Table 1) and (Fig. 3). Each mix has been homogenized and grinded individually for $5 \mathrm{~h}$ before wetting it by adding $14 \%$ water. The mix was homogenized by running it multiple times through a 2 and $1 \mathrm{~mm}$ sieve respectively. Mixtures have been sealed in nylon bags for $24 \mathrm{~h}$ in order to homogenize the moisture in the mixture. 
Table 1. Combination of cordierite-mullite mixtures and their incineration temperatures

\begin{tabular}{|c|c|c|c|c|}
\hline Mixture (Group) & Sample No. & Firing temperature ${ }^{\circ} \mathrm{C}$ & Cordierite \% & Mullite \% \\
\hline \multirow{4}{*}{ A } & $\mathrm{A} 1$ & 1300 & \multirow{4}{*}{30} & \multirow{4}{*}{70} \\
\hline & $\mathrm{A} 2$ & 1350 & & \\
\hline & A3 & 1400 & & \\
\hline & A4 & 1450 & & \\
\hline \multirow{4}{*}{ B } & B1 & 1300 & \multirow{4}{*}{40} & \multirow{4}{*}{60} \\
\hline & $\mathrm{B} 2$ & 1350 & & \\
\hline & B3 & 1400 & & \\
\hline & B4 & 1450 & & \\
\hline \multirow{4}{*}{ C } & $\mathrm{C} 1$ & 1300 & \multirow{4}{*}{50} & \multirow{4}{*}{50} \\
\hline & $\mathrm{C} 2$ & 1350 & & \\
\hline & $\mathrm{C} 3$ & 1400 & & \\
\hline & $\mathrm{C} 4$ & 1450 & & \\
\hline \multirow{4}{*}{ D } & D1 & 1300 & \multirow{4}{*}{60} & \multirow{4}{*}{40} \\
\hline & $\mathrm{D} 2$ & 1350 & & \\
\hline & D3 & 1400 & & \\
\hline & D4 & 1450 & & \\
\hline \multirow{4}{*}{$\mathbf{E}$} & E1 & 1300 & \multirow{4}{*}{70} & \multirow{4}{*}{30} \\
\hline & E2 & 1350 & & \\
\hline & E3 & 1400 & & \\
\hline & E4 & 1450 & & \\
\hline
\end{tabular}
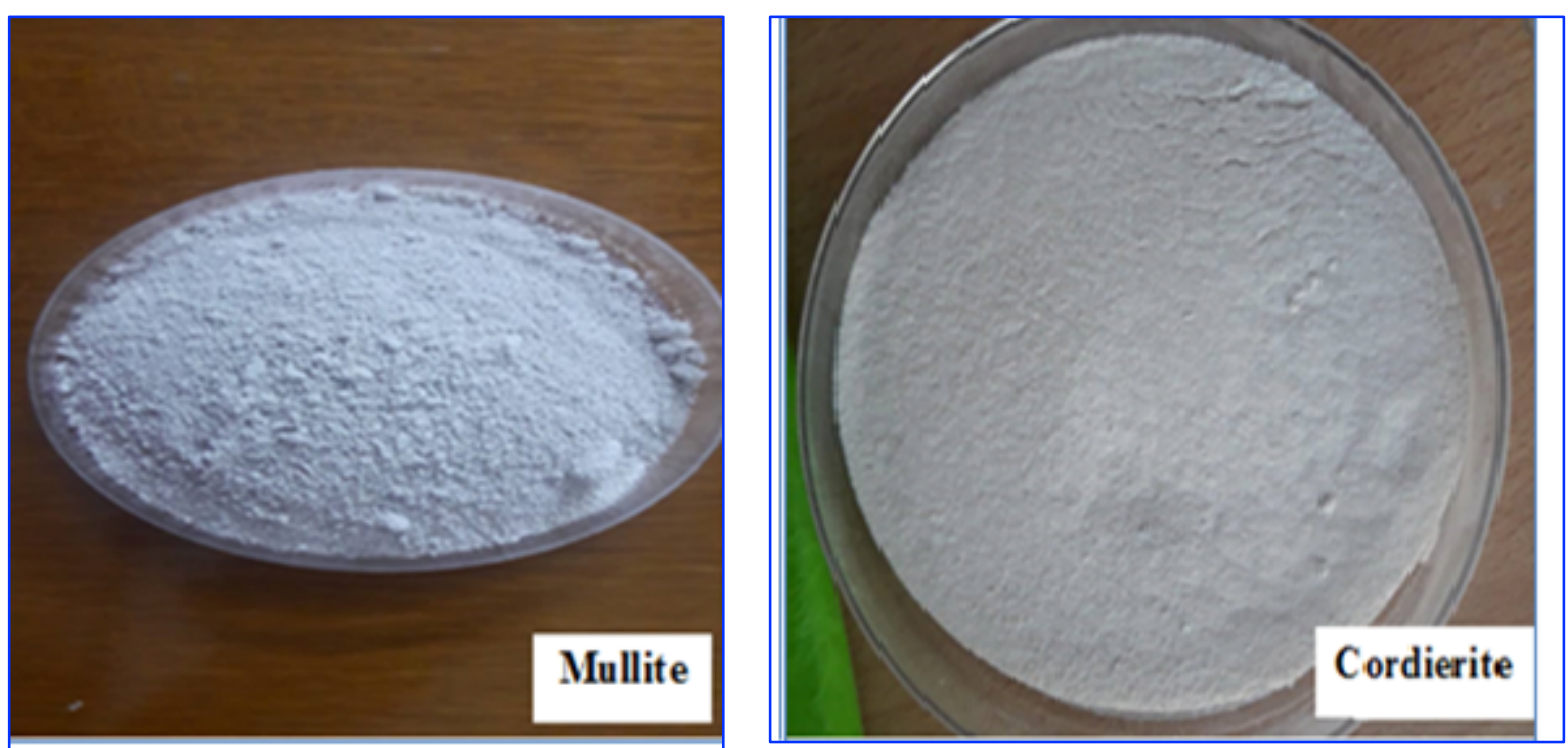

Fig. 3. Prepared mullite and cordierite powders

\section{Preparation of the Samples}

Twenty-four samples are crushed individually to obtain dense ceramic bodies to a particle size smaller than $45 \mu$ were prepared from each mixture making the total of 120 samples. The samples, which were pressed using the semi dry pressing method, took the shape of cylindrical disks with the radius of $4 \mathrm{~cm}$ and the thickness of $0.4 \mathrm{~cm}$ (Fig. 4). 


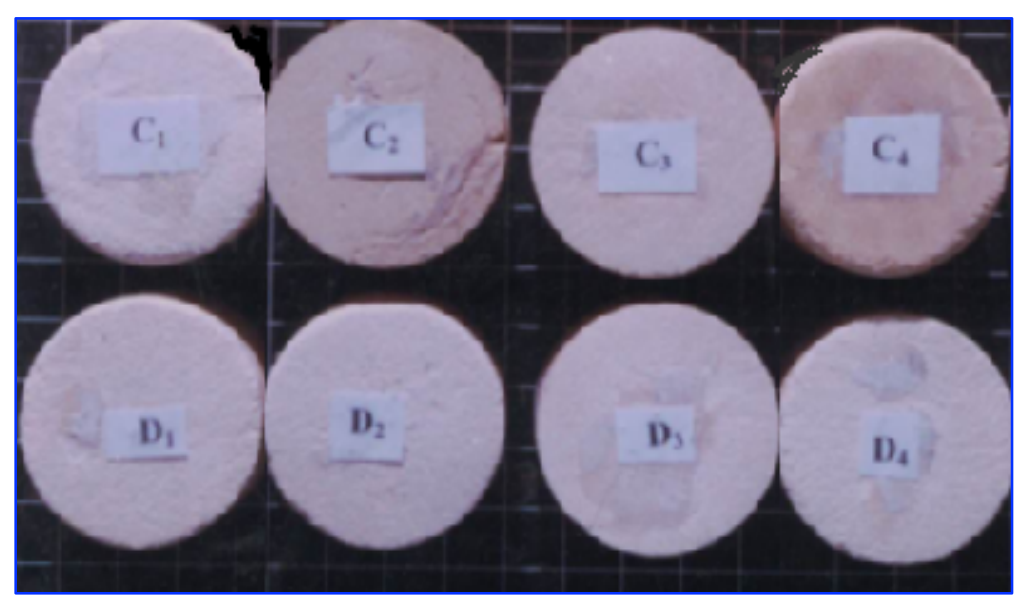

Fig. 4. Some prepared samples C1, C2, C3, C4, D1, D2, D3, and D4

The cylindrical disks were prepared by a hydraulic uniaxial press type (HERZOG) with the pressure of $1000 \mathrm{Kg} / \mathrm{cm}^{2}$ to achieve the highest closing up of particles and to obtain strong and hard samples. Using high pressure can achieve low shrinkage, which results from firing as well as increasing the density of the resulting product.

\section{Drying and Firing}

The samples have been dried at $105^{\circ} \mathrm{C}$ for $24 \mathrm{~h}$ using an electric oven in order to get rid of the added water slowly to prevent cracking due to fast evaporation and to give strength to the pressed samples in order to handle the samples easily. The samples were fired at temperatures of $1300,1350,1400$, and $1450^{\circ} \mathrm{C}$ using a specific firing program with temperature rise rate 50 ${ }^{\circ} \mathrm{C} / \mathrm{h}$ and soaking time of $2 \mathrm{~h}$. Later, the samples were taken out of the furnace after $24 \mathrm{~h}$. Shut down the furnace to give the metallic phases enough time to react and crystallize. The firing stage is considered the most complicated and most important stage because it involves a number of physical and chemical operations that give the ceramic body strength and toughness. The firing stage was performed at the Geological Survey Laboratories, Iraq. After the firing stage is complete, a number of evaluations tests were conducted for the resulting samples. These tests include; physical tests (volume shrinkage after firing, apparent porosity, water absorption, and bulk density) and mechanical tests (compressive strength).

\section{RESULTS AND DISCUSSIONS}

\section{Cordierite and Mullite Preparation}

Cordierite and mullite ceramics were prepared from Iraqi raw materials as a first part of the research project. The x- ray diffraction pattern for mullite and cordierite is presented in Fig. 5. Mullite and cordierite have been separately crushed using a porcelain ball crusher before each powder was sieved using a $45 \mu$ sieve. Powders were later stored in nylon sealed bags. 

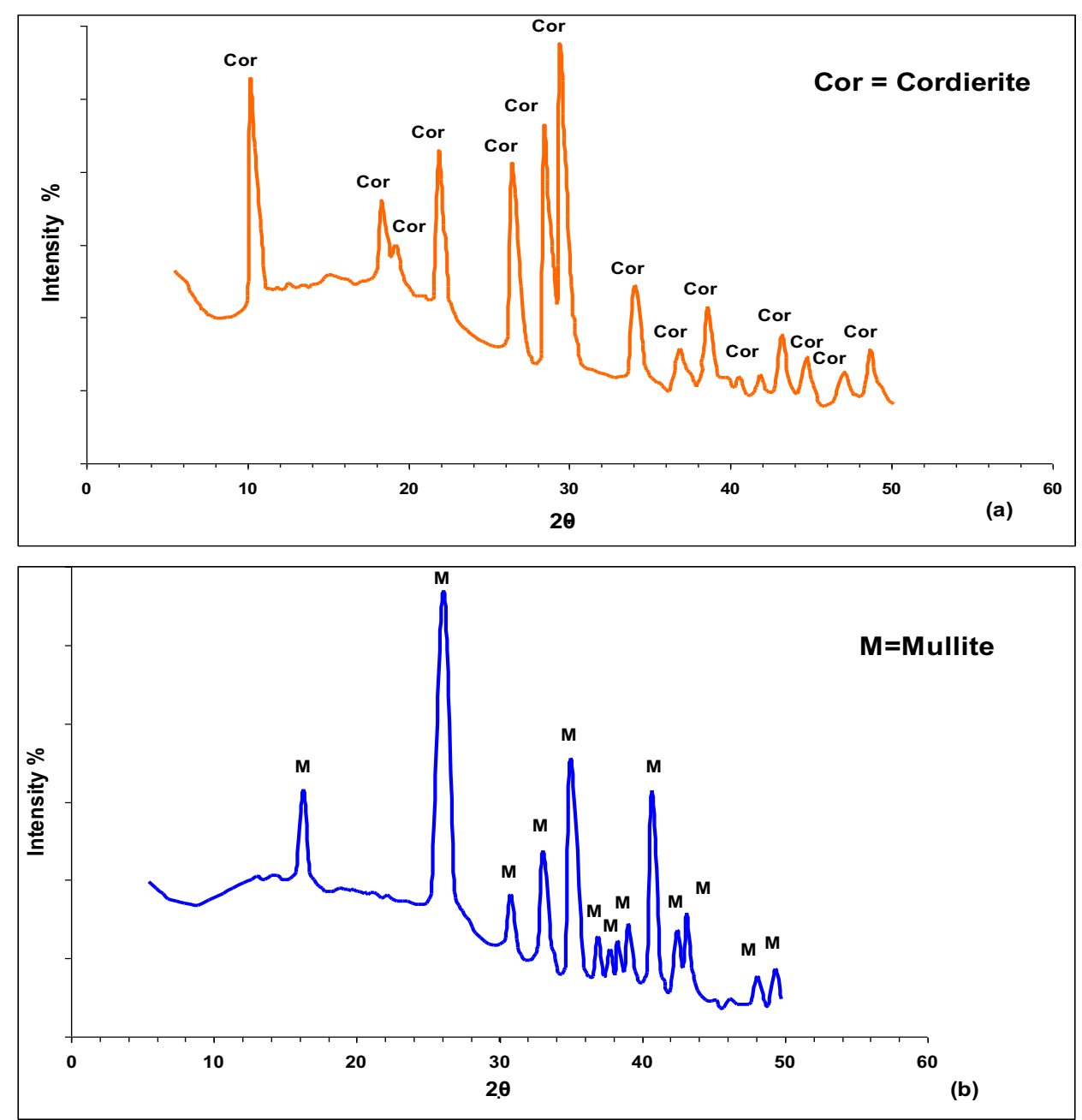

Fig. 5. X- ray diffractograms a. cordierite, and b. mullite

\section{Physical Properties}

\section{Volume shrinkage}

Table 2 and Fig. 6 shows the results of the volume shrinkage tests for samples that were fired at $1300,1350,1400$, and $1450{ }^{\circ} \mathrm{C}$, samples can be sorted into five groups which are: $\mathrm{A}, \mathrm{B}, \mathrm{C}$, $\mathrm{D}$, and $\mathrm{E}$.

Table 2. Volume shrinkage values for samples fired at $1300,1350,1400$, and $1450^{\circ} \mathrm{C}$

\begin{tabular}{|c|c|c|c|c|}
\hline \multirow{2}{*}{ Group } & \multicolumn{4}{|c|}{ Firing Temperature oC } \\
\cline { 2 - 5 } & $\mathbf{1 3 0 0}$ & $\mathbf{1 3 5 0}$ & $\mathbf{1 4 0 0}$ & $\mathbf{1 4 5 0}$ \\
\hline $\mathbf{A}$ & $6.28 \%$ & $12.00 \%$ & $11.97 \%$ & $10.00 \%$ \\
\hline B & $6.20 \%$ & $11.80 \%$ & $11.90 \%$ & $11.54 \%$ \\
\hline C & $6.15 \%$ & $11.68 \%$ & $11.62 \%$ & $12.00 \%$ \\
\hline D & $6.00 \%$ & $11.49 \%$ & $11.43 \%$ & $15.40 \%$ \\
\hline E & $5.51 \%$ & $11.09 \%$ & $12.12 \%$ & $14.32 \%$ \\
\hline
\end{tabular}




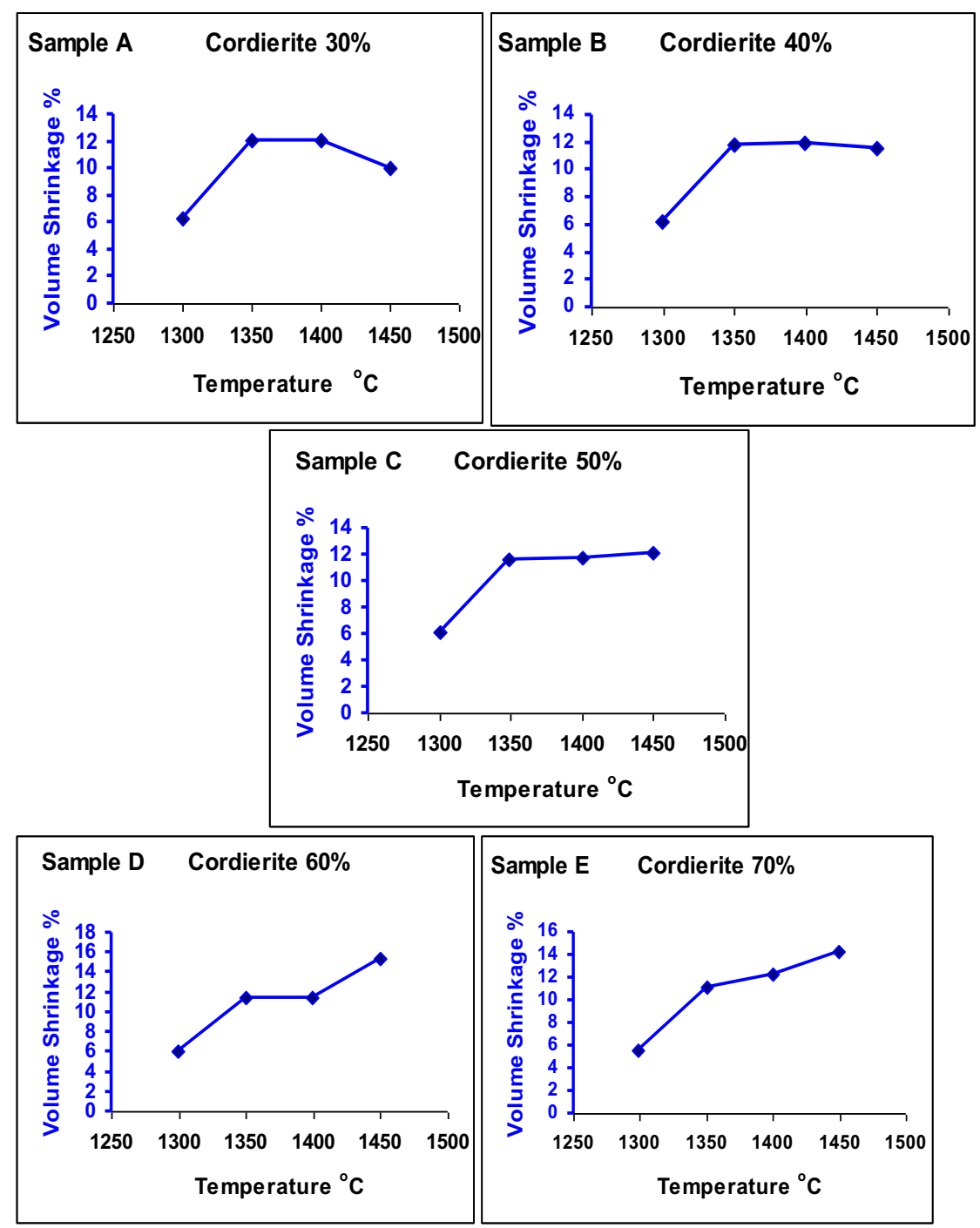

Fig.6. Samples volume shrinkage with the firing temperature change

The results show that all samples of these groups display a low volume shrinkage when fired at $1300{ }^{\circ} \mathrm{C}$. Volume shrinkage was between 5.51 and $6.28 \%$ because disappearance of the liquid glass phase between the two materials particles (codierite and mullite) which works to bring them closer together (Li et al., 2020).

When the firing temperatures for the groups $\mathrm{A}$ and $\mathrm{B}$ is between $1300-1400{ }^{\circ} \mathrm{C}$, an increase in the volume shrinkage for the samples. With the increase of temperature to 1450 ${ }^{\circ} \mathrm{C}$, we can notice a slight decrease in the volume shrinkage for both groups A and B, which was due to the increase of the firing temperature to more than $1350{ }^{\circ} \mathrm{C}$, the structure of cordierite starts to partially break down that helps the sintering process as well as the appearance of the liquid glass phase which reduces the volume of pores and blocks them that leads to the increase in volume shrinkage for the ceramic samples (Tabit et al., 2018). 
With the increase of temperature to $1450{ }^{\circ} \mathrm{C}$, according to Hodge (1985), the temperature of $1355{ }^{\circ} \mathrm{C}$ is the lowest temperature at which the stable liquid phase forms below the melting point of cordierite in the $\mathrm{MgO}-\mathrm{AL}_{2} \mathrm{O}_{3}-\mathrm{SiO}_{2}$ system, but by increasing the temperature to $1450{ }^{\circ} \mathrm{C}$, the cordierite melts accompanied by an increase of the volume of both closed and opened porosities. The quantity of the glass phase that formed from the melting of cordierite in the two groups wasn't enough to fill all the porosities. The existence of closed porosities poses a resistance to the volume shrinkage.

Sample of groups C, D, and E has a high increase in the percentage of volume shrinkage with the increase of the firing temperature from 1300 to $1450{ }^{\circ} \mathrm{C}$ where it was 6.15 $12 \%, 6-15.40 \%$, and 5.51-14.32\% respectively. It should be pointed that the samples of the groups $\mathrm{E}$ and $\mathrm{D}$ underwent warping at $1450{ }^{\circ} \mathrm{C}$, due to this, the volume shrinkage for the samples is not accurate. Because with the firing temperature increases, the particle closeness increases due to the sintering process, as well as the emergence of the liquid phase, which closes a certain percentage of the pores, and this depends on the amount of glass material formed, which depends on the components of the samples, their type, the size of their particles and the temperature (Norton, 1974). When these samples are cooled, the liquid glass freezes, the particles in the samples are joined together, the porosity ratio decreases and the volumetric shrinkage ratio of the samples increases (Tabit et al., 2018).

Cordierite added to these groups $(50,60$, and 70$) \%$ respectively which is the reason for the increase in the liquid glass phase that works on filling a large portion of the porosities between the particles, therefore the porosity is reduced and then undergoes verification at high temperatures causing a reduction in its apparent porosity and an increase in its density hence an increase in its shrinkage (Gonzales et al., 1992). We notice that the highest shrinkage rate for the samples was for the samples containing 30\% mullite and $70 \%$ cordierite for all firing temperatures. The smallest volume shrinkage rates were for samples containing $30 \%$ cordierite and $70 \%$ mullite.

\section{Water absorption and apparent porosity}

Fig.7, Table 3, and Table 4 illustrates the relation between water absorption and apparent porosity in different firing temperatures where the percentage of cordierite remains constant. On the basis of these percentages, we can split samples into 5 groups. It is noticed that all samples A, B, C, D, and E that contain 30, 40, 50, 60 and $70 \%$ cordierite respectively display a high apparent porosity as well as high water absorption at $1300{ }^{\circ} \mathrm{C}$. These high readings due to the firing temperature were not sufficient for the sintering process between the ceramic 
particles, therefore the low quantity of the liquid glass phase which was not enough to fill the opened and closed porosities between the particles that caused to have a high percentage of apparent porosity as well as high water absorption rates (Warrir et al., 1989). With the increase of the firing temperature from $1300-1350^{\circ} \mathrm{C}$, a sudden, considerable decrease occurs in the porosity and the water absorption for all groups A, B, C, D and E. then a slight increase when the firing temperature is increased to $1450^{\circ} \mathrm{C}$ for groups $\mathrm{A}, \mathrm{B}$, and $\mathrm{C}$.
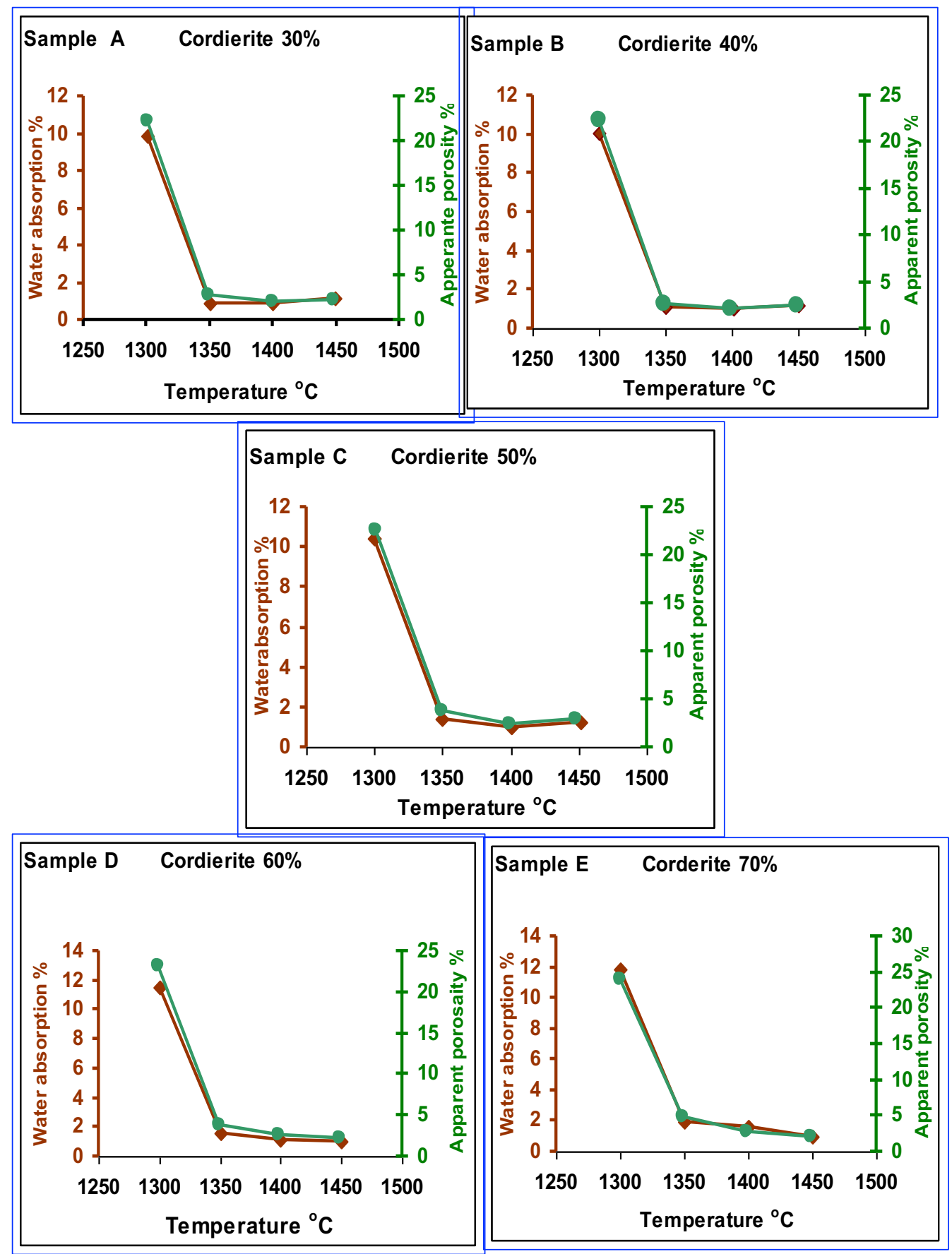

Fig. 7. The relationship between water absorption and apparent porosity of samples with the firing temperature change 
Table 3. Water absorption values for samples fired at $1300,1350,1400$, and $1450{ }^{\circ} \mathrm{C}$

\begin{tabular}{|c|c|c|c|c|}
\hline \multirow{2}{*}{ Group } & \multicolumn{4}{|c|}{ Firing Temperature $^{\mathbf{0}} \mathbf{C}$} \\
\cline { 2 - 5 } & $\mathbf{1 3 0 0}$ & $\mathbf{1 3 5 0}$ & $\mathbf{1 4 0 0}$ & $\mathbf{1 4 5 0}$ \\
\hline $\mathbf{A}$ & $9.86 \%$ & $0.91 \%$ & $0.90 \%$ & $1.16 \%$ \\
\hline $\mathbf{B}$ & $10.05 \%$ & $1.07 \%$ & $0.978 \%$ & $1.16 \%$ \\
\hline $\mathbf{C}$ & $10.46 \%$ & $1.46 \%$ & $1.10 \%$ & $1.28 \%$ \\
\hline $\mathbf{D}$ & $11.49 \%$ & $1.58 \%$ & $1.17 \%$ & $1.01 \%$ \\
\hline $\mathbf{E}$ & $11.71 \%$ & $1.97 \%$ & $1.60 \%$ & $1.00 \%$ \\
\hline
\end{tabular}

Table 4. Apparent porosity values for samples fired at $1300,1350,1400$, and $1450{ }^{\circ} \mathrm{C}$

\begin{tabular}{|c|c|c|c|c|}
\hline \multirow{2}{*}{ Group } & \multicolumn{4}{|c|}{ Firing Temperature ${ }^{\mathbf{}} \mathbf{C}$} \\
\cline { 2 - 5 } & $\mathbf{1 3 0 0}$ & $\mathbf{1 3 5 0}$ & $\mathbf{1 4 0 0}$ & $\mathbf{1 4 5 0}$ \\
\hline $\mathbf{A}$ & $22.30 \%$ & $2.71 \%$ & $2.08 \%$ & $2.29 \%$ \\
\hline $\mathbf{B}$ & $22.32 \%$ & $2.71 \%$ & $2.08 \%$ & $2.50 \%$ \\
\hline $\mathbf{C}$ & $22.61 \%$ & $3.73 \%$ & $2.48 \%$ & $2.89 \%$ \\
\hline $\mathbf{D}$ & $23.21 \%$ & $3.90 \%$ & $2.70 \%$ & $2.25 \%$ \\
\hline $\mathbf{E}$ & $24.15 \%$ & $4.73 \%$ & $2.90 \%$ & $2.00 \%$ \\
\hline
\end{tabular}

This was due to the fact that with the increase of the firing temperature, the particles get closer with one another due to the sintering process in addition to the creation of the liquid glass phase that works on filling the spaces between the pores in the ceramic samples which causes its percentages to decrease (Grim, 1971). The decrease in porosity directly leads to the decrease in water absorption and with the increase of the firing temperatures, the cordierite starts to fuse and causes an increase in the percentages of closed and opened porosities that directly leads to the increase in the water absorption percentages for samples ( $\mathrm{Li}$ et al., 2020). The samples of the groups E and D show significant decrease in the percentages of apparent porosities and water absorption with increase of the firing temperature from $1300-1450{ }^{\circ} \mathrm{C}$. Due to the sintering process the particles close together in addition to creating a liquid glass phase, which works on filling the porosities and reduce their proportions, and then vitrification occurs at high temperatures that increases its surface tension, decreases the apparent porosity and decrease the water absorption.

\section{Bulk density and apparent porosity}

The relationship of the bulk density and apparent porosity with the change of burning temperatures by the stability of the proportions added from the cordierite are presented in Fig. 8 and Table 5. Note that all samples indicated with A, B, C, D, and E are characterized by a gradual increase in the bulk density with an increase in the burning temperature from 1300 $1400{ }^{\circ} \mathrm{C}$, ranging from $2.05-2.69 \mathrm{~g} / \mathrm{cm}^{3}$ for all samples. This is due to the fact that with the burning temperature rising to more than $1350{ }^{\circ} \mathrm{C}$, the crystalline structure of the cordierite 
begins to break down (softening), and this works to obtain the sintering process between the particles of the cordierite and the mullite, the two main components of the samples, as well as increasing the amount of liquid glass phase (cordierite glass and glass) which closes a certain percentage of the pores of these samples (depends on the proportion of the cordierite in the samples), depending on the amount of the formed glass material which in turn depends on the amount and type of components of the burnt substance, the size of their particles, and the firing temperature (Norton, 1974; Sknath and Rakesh, 2014).

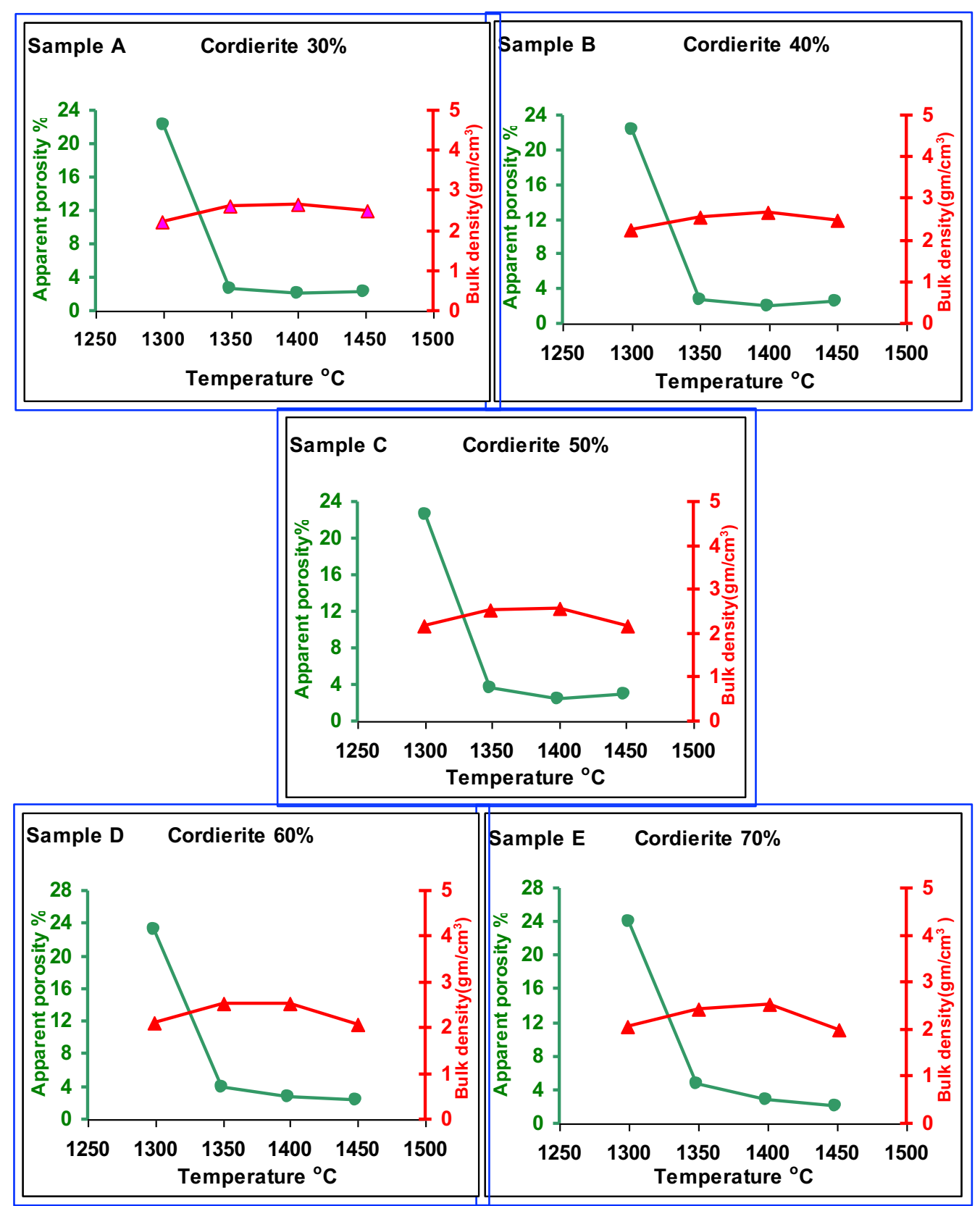

Fig. 8. The relationship between bulk density and apparent porosity with the firing temperatures change 
Table 5. The bulk density values for samples fired at $1300,1350,1400$, and $1450{ }^{\circ} \mathrm{C}$

\begin{tabular}{|c|c|c|c|c|}
\hline \multirow{2}{*}{ Group } & \multicolumn{4}{|c|}{ Firing Temperature ${ }^{\mathbf{}} \mathbf{C}$} \\
\cline { 2 - 5 } & $\mathbf{1 3 0 0}$ & $\mathbf{1 3 5 0}$ & $\mathbf{1 4 0 0}$ & $\mathbf{1 4 5 0}$ \\
\hline $\mathbf{A}$ & $2.22 \%$ & $2.64 \%$ & $2.67 \%$ & $2.49 \%$ \\
\hline $\mathbf{B}$ & $2.26 \%$ & $2.57 \%$ & $2.67 \%$ & $2.47 \%$ \\
\hline $\mathbf{C}$ & $2.17 \%$ & $2.55 \%$ & $2.60 \%$ & $2.18 \%$ \\
\hline $\mathbf{D}$ & $2.11 \%$ & $2.55 \%$ & $2.55 \%$ & $2.08 \%$ \\
\hline $\mathbf{E}$ & $2.05 \%$ & $2.44 \%$ & $2.53 \%$ & $1.98 \%$ \\
\hline
\end{tabular}

When these samples cool, the liquid glass phase solidifies, and the particles are bounded together, their porosity decreases, the bulk density of the samples increases. When the burning temperature increases to $1450{ }^{\circ} \mathrm{C}$ for the samples of the groups $\mathrm{A}, \mathrm{B}, \mathrm{C}, \mathrm{D}$, and $\mathrm{E}$, a decrease in the bulk density was observed. Temperture of the cordierite were increased from 30-70\%, increases amount of the porous (open and closed) resulting from the melting of cordierite, and the amount of the liquid phase (cordierite glass and glass) was not sufficient to fill all these pores, so the percentage of porosity of the samples increased, which leads to a decrease in the bulk density. Therefore it is noted that the lowest value of the bulk density was for the samples containing $70 \%$ of the cordierite.

\section{Mechanical Properties}

\section{Compressive strength}

Fig. 9 and Table 6 illustrates the relationship of compressive strength and the firing temperatures with the constancy of the added proportions of the cordierite. It is noted that the samples A, B, C, D, and E all have a gradual increase in the compressive strength with an increase in the burning temperature from $1300-1400{ }^{\circ} \mathrm{C}$. The values ranged between 61.5 $69.2 \mathrm{~kg} / \mathrm{cm}^{3}$ for all samples. When the firing temperature rises to $1450^{\circ} \mathrm{C}$, a decrease in the values of compressive strength is observed. The increase in the firing temperature from 1300 - $1400{ }^{\circ} \mathrm{C}$, The crystalline structure of the cordierite of the samples begins to collapse (softening), the sintering process occurs, an increase in the the particles close together, and appearance of a liquid phase that reduces the size of the pores and closes them. After solidification on cooling, the density increases, and the samples become more tough and strong, and their compressive strength increases. 


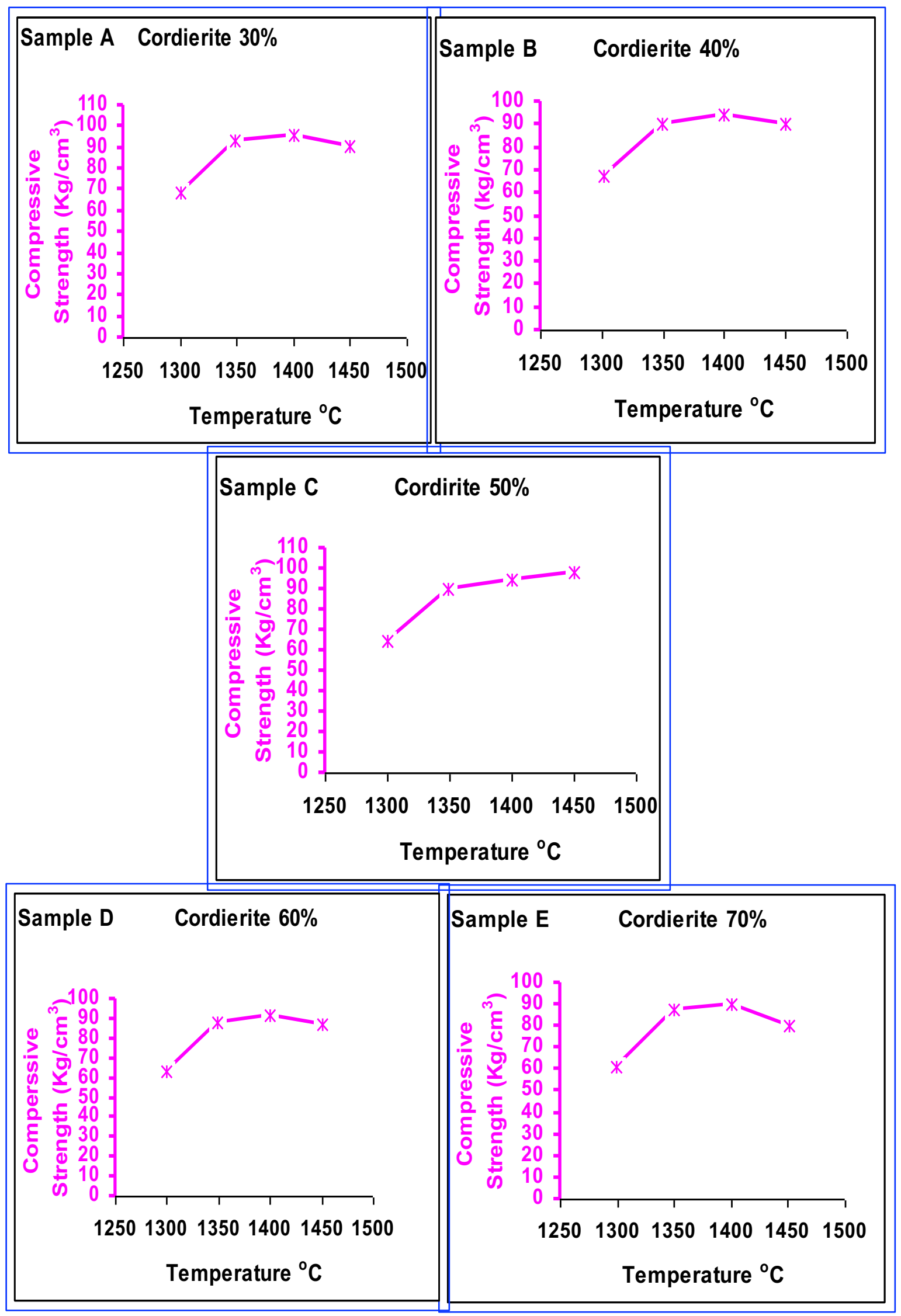

Fig. 9. The relationship between compressive strength with the firing temperatures 
Table 6. The compressive strength for samples fired at $1300,1350,1400$, and $1450{ }^{\circ} \mathrm{C}$

\begin{tabular}{|c|c|c|c|c|}
\hline \multirow{2}{*}{ Group } & \multicolumn{4}{|c|}{ Firing Temperature ${ }^{\mathbf{C}}$} \\
\cline { 2 - 5 } & $\mathbf{1 3 0 0}$ & $\mathbf{1 3 5 0}$ & $\mathbf{1 4 0 0}$ & $\mathbf{1 4 5 0}$ \\
\hline $\mathbf{A}$ & $69.00 \%$ & $93.30 \%$ & $96.20 \%$ & $90.50 \%$ \\
\hline $\mathbf{B}$ & $67.40 \%$ & $90.10 \%$ & $94.30 \%$ & $90.10 \%$ \\
\hline $\mathbf{C}$ & $65.10 \%$ & $89.80 \%$ & $94.30 \%$ & $98.60 \%$ \\
\hline $\mathbf{D}$ & $63.70 \%$ & $88.40 \%$ & $92.10 \%$ & $86.60 \%$ \\
\hline $\mathbf{E}$ & $61.50 \%$ & $87.50 \%$ & $89.80 \%$ & $80.30 \%$ \\
\hline
\end{tabular}

\section{CONCLUSIONS}

1. Physical and mechanical evaluation tests showed that the samples with constant firing temperature and an increase in the percentage of cordierite (30-70)\%. Decreased in density, volumetric shrinkage, and compression strength, but the porosity and water absorption increases.

2. The burnt samples at a temperature of $1450{ }^{\circ} \mathrm{C}$ with a cordite percentage (60-70\%). An increase in volumetric shrinkage and a decrease in porosity and water absorption are observed.

3. When the percentage of cordierite in the samples is constant and increase the burning temperature from $1300-1450{ }^{\circ} \mathrm{C}$. A decrease in the apparent porosity, water absorption, increased density, volumetric shrinkage ratio and compressive strength were observed for the samples.

4. By compared the results of samples (physical and mechanical), it was found that the best ceramic samples for all added percentages of cordierite, with firing temperature 1300 , 1350, 1400, and $1450{ }^{\circ} \mathrm{C}$, are samples with the symbol A1, A2, A3 and A4, respectively, it contains $30 \%$ cordierite and $70 \%$ mullite.

5. It has been verified that the optimal sample for all study samples is symbol A3; it contains $30 \%$ cordierite and $70 \%$ mullite, and burns at a temperature of $1400{ }^{\circ} \mathrm{C}$.

6. Adding 30 and $40 \%$ cordierite to mullite and burning their samples at temperatures of 1350 , and $1400{ }^{\circ} \mathrm{C}$, improves the physical and mechanical properties of the samples.

7. Using 50,60 and 70\% cordierite in the cordierite and mullite samples may weaken the physical and mechanical properties of the samples.

\section{ACKNOWLEDGMENTS}

The authors gratefully acknowledge the support from the staff in the University of Technology, Applied Science Department, Material Science, for their valuable efforts during the study. The authors are very grateful to the Editor in Chief Prof. Dr. Salih M. Awadh, the 
Secretary of Journal Mr. Samir R. Hijab and the Technical Editor Dr. Heba S. Al-Mimar for their great efforts and valuable comments.

\section{REFERENCES}

Akpinar, S., Kus, I. .M., Ertugrul oglu O., and Onel, K., 2015 .Microwave assisted sintering of in-situ cordierite foam. Ceramic International, $41: 8605-8613$.

Anggono, J., 2005. Mullite Ceramics: Its Properties, Structure, and Synthesis. Journal Teknik Mesin, 7 (1):1 10.

Bras, W., Clark, S. M., Greaves, G. N., Kunz, M., Van Beek, W., and Radmilovic, V., 2009. Nanocrystal growth in cordierite glass ceramics studied with X-ray scattering. Crystal Growth, 1297-1305.

Chester, H. S, 1973. Refractories production and properties. Lund Humphries. Brad ford.

Gonzales, L., Leon, M., and Galan, E., 1992. Assessment of the ceramic uses of clay from Southern Spain form compositional, drying forming data, Gological Carpathica, Series Clay, 2 Bratislava: 97-100.

Grim, S.R., 1971. The Chemistry and Physics of Clay. Ernestbeen, Itd., London.

Grosjean, P., 1993. Cordierite ceramics. Interceram, 42(1):11-15.

Hamzawy, E. M. A., and Ali, A. F., 2006. Solgel preparation of boron containing cordierite $\mathrm{Mg}_{2}(\mathrm{Alx} 4 \mathrm{Bx}) \mathrm{Si}_{5} \mathrm{O}_{8}$ and its crystallization. Material Characteristics, 57(4-5): 414-418.

Hodge, J. D., 1985. Densification and Micro structural aspects of Mullite-Cordierite Ceramic. Technical Information Series. New York.

Li, H., Li, C., Wu, L., Wang, H., Li, J., Fu, M., and Wang, C., 2020. Near net size sintering of porous cordierite ceramics with excellent properties. Journal of Alloys and Compounds, 826 154121:1-8.

Norton, F. H., 1974. Element of Ceramics. $2^{\text {nd }}$ Ed., Addition-Wesley Publishing company Inc.: 311.

Pask, J. A., 1988. Phase equilibria in the $\mathrm{Al}_{2} \mathrm{O}_{3}-\mathrm{SiO}_{2}$ system with emphasis on mullite. Materials Science Forum, 34-36: 1-8.

Rasteiro, M. G., Gassman, T., Santos, R., and Antunes, E., 2007. Crystalline phase characterization of glassceramic glazes. Ceramics International, 33: 345 .

Sabri, I., 2001. Preparing Mullite from Local Materials. M. Sc Thesis, University of Baghdad, Iraq.

Sembiring, S., Simanjuntak, W., Situmeang, R., Riyanto, A., and Sebayang, K., 2016. Preparation of refractory cordierite using amorphous rice husk silica for thermal insulation purposes. Ceramics International 42: 8431-8433.

Shukur, M. M., 2002. Preparation of Cordierite from Local Raw Material. Ph. D Thesis, University of Baghdad, Iraq.

Shyam, A., Lara-Curzio, E., Pandey, A., Watkins, T. R., and More, K. L., 2012. The thermal expansion, elasticand fracture properties of porous cordierite at elevated temperatures. Journal of American Ceramic. Society, 95: 6-8.

Sknath, S. K. and Rakesh, K., 2014. Effect of mechanical activation on cordierite synthesis through solid-state sintering method. Bulletin Material Science, 37(6): 1221-1226.

Suriyanarayanan, N., Kannan Nithin, K.V., and Bernardo, E., 2009. Mullite glass ceramics production from coal ash and alumina by high temperature plasma. Journal of Non-Oxide Glasses, 1(4): 247.

Tabit, K., Waqif, M., and Saâdi, L., 2018. Crystallization behavior and properties of cordierite synthesized by sol-gel technique and hydrothermal treatment. Journal of the Australian Ceramic Society: 6-7.

Warrir, K. G. K., Mukundan, P., Pillai, P.K. and Dam odran, A. D., 1989. Particle Size of quartz and the verification of porcelain. International Ceramic, 28 (5). 